\title{
Aprendizagens de uma pandemia como oportunidade a não perder e ameaça a evitar
}

Rui Nogueira*

$\mathrm{H}$ oje, dia 27 de setembro, foi ultrapassado um milhão de pessoas vítimas de COVID-19 em todo o mundo. Com mais de 33 milhões de casos positivos para o SARS-Cov-2, um novo normal está a ser criado em todas as dimensões que sejam apreciadas nas diferentes comunidades em todo o mundo. Em 11 de março de 2020, a Organização Mundial da Saúde declarou a pandemia COVID $19^{1}$ e recomendou "ações urgentes e agressivas" aos governos para mudar o rumo da situação. ${ }^{2}$ As consequências desta pandemia ainda são inimagináveis e ainda falta saber o que nos vai acontecer nos próximos meses, seja pela COVID-19 seja pelo seu efeito adverso sobre todos os doentes não-COVID-19!

Em Portugal foi declarado o estado de emergência pelo Decreto do Presidente da República n. ${ }^{\circ}$ 14-A/2020, de 18 de março, renovado pelos Decretos do Presidente da República n. ${ }^{\circ}$ 17-A/2020, de 2 de abril, e 20-A/2020, de 17 de abril, prolongando-se até às 24 horas do dia 1 de maio. Ao estado de emergência seguiu-se o estado de calamidade até 30 de junho e depois o estado de alerta.

O desconfinamento em Portugal foi realizado em três fases, sucessivamente em 4 e 18 de maio e 1 de junho, sem repercussão epidemiológica apreciável na evolução da pandemia.

Estamos, desde 15 de setembro de 2020, em estado de contingência em todo o país para dar resposta às necessidades especiais das comunidades no início do Outono e perante o agravamento epidemiológico da pandemia na Europa e previsível em Portugal após a reabertura das escolas.

Com base nos dados dos boletins diários da Direção-Geral da Saúde (DGS), desde 3 de abril tivemos diariamente mais de $90 \%$ dos casos COVID-19 em isolamento no domicílio e seguidos essencialmente pelos médicos de família de cada unidade de saúde, de acordo com a Norma n. ${ }^{\circ}$ 04/2020, de 23 de março, da DGS. ${ }^{3}$

*USF Norton de Matos, ACeS Baixo Mondego.
Com base nos boletins diários da DGS, o número máximo de doentes internados em serviços hospitalares de cuidados intensivos foi atingido em 6 de abril, com 271 doentes, correspondendo a $2,3 \%$ dos casos ativos nesse dia. $\mathrm{O}$ número máximo de internamentos em serviços hospitalares foi atingido em 15 de abril, com 1.073 doentes internados, correspondendo a $6,1 \%$ dos casos ativos nesse dia.

As medidas decretadas pelo Governo e adotadas pela sociedade criaram novas dinâmicas nas unidades de saúde. Os centros de saúde desenvolveram planos de ação de modo a dar respostas organizadas, adaptadas e seguras para os seus doentes habituais, principalmente aos portadores de doença crónica e a grupos vulneráveis como crianças e mulheres grávidas.

No início da pandemia, em março de 2020, era já conhecido que a COVID-19 representava um risco para a população idosa e com doenças crónicas. ${ }^{2}$ Não é, pois, de estranhar que as medidas concretas para responder às exigências desta pandemia tenham que ser concentradas e muito dirigidas às pessoas idosas, aos seus cuidadores e a todos quantos trabalham nesta área.

Num estudo recente sobre mais de 20 mil doentes internados em 208 hospitais do Reino Unido por COVID-19, publicado recentemente no BMJ, ${ }^{4}$ é referida uma taxa de mortalidade de $26 \%$ entre os doentes internados e a admissão de $17 \%$ em cuidados intensivos com uma taxa de mortalidade de $32 \%$. O estudo pretendeu estudar os fatores de risco associados à mortalidade e reporta-se ao período de 6 de fevereiro a 19 de abril 2020, com análise em 3 de maio, pelo que $34 \%$ dos doentes admitidos nos hospitais ainda estavam internados nesta data. A mortalidade é elevada e a idade do doente, o sexo masculino e as doenças crónicas, incluindo a obesidade, são os fatores de risco mais importantes.

Na nossa fase mais difícil da primeira vaga - segunda quinzena de março e primeira quinzena de abril - tivemos sempre taxas de internamento em unidades de cuidados intensivos superiores a $20 \%^{3} \mathrm{e}$, no final de março, 
tivemos vários dias com mais de $25 \%$ dos doentes internados em unidades de cuidados intensivos. Em 12 abril, a taxa de internamentos em cuidados intensivos começou a baixar, mantendo-se quase todos os dias entre $15 \%$ e $20 \%$ até ao início de julho e depois sempre abaixo de $15 \%$ dos doentes internados. Desde o início de setembro, em Portugal a taxa de doentes internados em unidades de cuidados intensivos varia entre os $14 \%$ e os $16 \%$.

As pessoas residentes em lares correm maior risco de adquirir COVID-195 e, por serem idosos e portadores de doenças crónicas, serão doentes mais graves, com maior risco e maior letalidade.

Em Espanha, ${ }^{6} 66 \%$ das pessoas que faleceram no início de junho residiam em lares, com 27.940 óbitos referidos nessa altura.

Em 2 de abril de 2020, os geriatras Nathan Stall e Samir Sinha relataram ${ }^{7}$ o que aconteceu num lar de idosos (Bobcaygeon's Pinecrest Nursing Home) em Ontário, Canadá, como "um surto catastrófico de coronavírus que matou 14 residentes e um cônjuge visitante". Com pelo menos 24 funcionários infetados, a tragédia é comparada a uma "zona de guerra". Infelizmente não é um caso único e os autores referem haver problemas em mais de 600 lares de idosos no Canadá.

Em Ontário residem cerca de 14,6 milhões de pessoas (dados de 2019) e há cerca de 400 mil pessoas (2,7\% da população) a residir em lares de idosos para cuidados de longa duração. ${ }^{7}$ A idade média dos residentes é de 82 anos e $61 \%$ destes doentes toma 10 medicamentos por dia. Cerca de $90 \%$ têm alguma forma de deficiência cognitiva e $64 \%$ têm demência, $80 \%$ tem doença neurológica, $40 \%$ necessitam de acompanhamento médico por doença aguda e a maioria das pessoas residentes nestes lares requer cuidados 24 horas por dia. No total são 629 residências dedicadas a pessoas dependentes. No entanto, é referido pela Ontario Long Term Care Association que cerca de metade destas residências têm instalações desadequadas e carecem de melhoria. Uma impressionante taxa de letalidade de $33,7 \%$ por COVID19 entre os residentes nos lares de Ontário é referida pelos geriatras Nathan Stall e Samir Sinha. ${ }^{7}$ Os idosos são frágeis e há maior probabilidade de apresentações atípicas, sem referência a tosse ou febre. "Durante um surto num lar de idosos no estado deWashington, quase metade de todos os residentes com teste positivo para COVID-19 não apresentaram sintomas no dia do teste." Os surtos em residências de idosos podem facilmente tornar-se muito graves e merecem, portanto, uma atenção especial.
Em 1 de janeiro de 2018, a população da UE-28 foi estimada em 512,4 milhões de pessoas e a idade mediana da população era de 43,1 anos (40,4 anos em 2008). As pessoas com 65 anos ou mais representavam uma quota de $19,7 \%$ (um aumento de 0,3 pontos percentuais relativamente ao ano anterior e de 2,6 pontos percentuais em comparação com 10 anos antes). A Itália (22,6\%) e a Grécia $(21,8 \%)$ registaram as percentagens mais altas de população idosa, enquanto a Irlanda tinha a percentagem mais baixa $(13,8 \%) .{ }^{8}$ Nesta referência, Portugal tinha $21,5 \%$ da população com 65 ou mais anos, um aumento de 3,8 pontos percentuais em relação a $2008(17,7 \%)$.

Segundo dados do INE publicados na PORDATA $^{9} \mathrm{e}$ atualizados em 15 de junho de 2020, a população residente em Portugal em 2019 era de 10,288 milhões, sendo 2,262 milhões a população residente com 65 ou mais anos, o que representa $22,0 \%$ da população. Com 80 ou mais anos, a população residente em Portugal em 2019 era de 668,66 mil (6,5\%).

Os doentes com 85 ou mais anos internados em hospitais em Portugal passou de cerca de 31 mil em 2000 para quase 120 mil em 2018, ${ }^{10}$ isto é, um aumento de cerca de quatro vezes em 18 anos. Em 2018, 43,1\% dos utentes com alta de internamento nos hospitais portugueses tinham 65 ou mais anos $\left(29,2 \%\right.$ em 2000). ${ }^{10}$

A esperança de vida à nascença em Portugal foi estimada em 80,8 anos no triénio terminado em 2018, sendo 83,4 anos no sexo feminino e 77,8 anos no sexo masculino. Mas a estimativa de anos de vida saudável à nascença era de 58,6 anos, sendo mais baixa para as mulheres (57,5 anos) do que para os homens (59,8 anos). A expectativa de vida aos 65 anos em Portugal ${ }^{10}$ foi estimada em 19,49 anos para o total da população no triénio terminado em 2018, sendo respetivamente de 17,58 anos e de 20,88 anos para os homens e para as mulheres com a mesma idade.

Em 2018 e em comparação com os restantes países da UE-28, Portugal posicionava-se em $10 .^{\circ}$ lugar, com 7,3 anos de vida saudável aos 65 anos, um valor inferior em 2,7 anos em relação à média europeia que era de 10,0 anos. Por outro lado, Portugal era em 2018 um dos países da União Europeia com maior diferença entre a expectativa de anos de vida saudável aos 65 anos para homens e para mulheres (mais 0,9 anos a favor dos homens). ${ }^{10}$

O Grupo de Estudos de Saúde do Idoso (GESI) da APMGF, com base na informação disponível a 29 de mar- 
ço de 2020, elaborou um conjunto de recomendações, ${ }^{11}$ entendidas como medidas excecionais para rápida aplicação e dirigidas a residências de idosos. Estas recomendações refletem a preocupação do GESI perante a pandemia do COVID-19 e o seu impacto particular na população idosa residente em lares.

O Fórum Económico Mundial está a promover uma iniciativa de resposta à crise COVID-19 - THE GREAT RESET $^{12}-$, salientando as inconsistências, inadequações e contradições de múltiplos sistemas (de saúde, financeiro, energia e educação). A iniciativa tem um conjunto de dimensões para construir um novo contrato social que honre a dignidade humana.

Estamos provavelmente perante uma oportunidade de desenvolvimento do Serviço Nacional de Saúde e de toda a arquitetura do nosso sistema de saúde. Parece necessário refletir e pensar num novo modelo residencial para idosos, tendo em conta a evolução demográfica dos últimos anos e a projeção já conhecida de envelhecimento populacional no futuro próximo. Conhecendo a necessidade de aumentar a lotação de residências de idosos, já elevada em muitos países europeus e ainda em crescimento em Portugal, tendo em conta o «novo normal», é inevitável iniciar o projeto de um novo modelo de residência, assistência e apoio aos idosos. O foco deverá ser a pessoa, numa abordagem humanista e digna, competente, adequada às necessidades e garantindo segurança.

As transformações vividas pelas comunidades em todo o mundo, com implicações evidentes em todos os setores de atividade, induziram e vão continuar a induzir profundas alterações na vida e nos projetos das pessoas e das organizações. Os hábitos de vida, os ritmos de trabalho, as relações sociais, as tradições culturais, as atividades desportivas, ou as simples opções de turismo e de lazer, em todos os setores de atividade, sem exceções, tiveram alterações profundas nos últimos seis meses. Mas nas áreas financeira, económica, laboral e política haverá muitas outras alterações. O problema de saúde conhecido hoje no início do Outono de 2020 vai muito para além da pandemia COVID-19. O Inverno demográfico que se vive há anos trará consequências em toda a organização social, com implicações muito para além da saúde e da atual pandemia.

Provavelmente será necessário repensar o ordenamento do território, estudar a demografia humana, desenvolver a política social e cultural, melhorar os transportes públicos, adaptar os aeroportos e programar as viagens e o turismo. Com profundas alterações previsíveis, em setores tão importantes e diversificados, como serão as alterações na área da saúde? O que é que vai mudar no setor da saúde? Nada vai ficar como antes!

O Serviço Nacional de Saúde adquire uma importância especial neste contexto de projeto de evolução e de investimento e é obrigatório reforçar a sua disponibilidade financeira e valorizar os recursos humanos, o seu principal património.

\section{REFERÊNCIAS BIBLIOGRÁFICAS}

1. World Health Organization. WHO Director-General's opening remarks at the media briefing on COVID-19 - 11 March 2020 [homepage]. Geneva: WHO; 2020.Available from: https://www.who.int/dg/speeches/detail/whodirector-general-s-opening-remarks-at-the-media-briefing-on-covid-19--11-march-2020

2. The Lancet Respiratory Medicine. COVID-19: delay, mitigate, and communicate. Lancet Respir Med. 2020;8(4):321.

3. Direção-Geral da Saúde. COVID-19: fase de mitigação.Abordagem do doente com suspeita ou infeção por SARS-CoV-2: norma n. ${ }^{\circ}$ 004/2020, de 23/03/2020, atualizada em 31/08/2020. Lisboa: DGS; 2020.

4. Docherty AB, Harrison EM, Green CA, Hardwick HE, Pius R, Norman L, et al. Features of 20133 UK patients in hospital with covid-19 using the ISARIC WHO Clinical Characterisation Protocol: prospective observational cohort study. BMJ. 2020;369:m1985.

5. Cowper B, Jassat W, Pretorius P, Geffen L, Legodu C, Singh S, et al. COVID19 in long-term care facilities in South Africa: no time for complacency. $S$ Afr Med J. 2020 September 4. [Epub ahead of print]

6. Blanco-Tarrio E, Blanco-Sánchez G. Atención primaria y residencias de ancianos: a propósito de la COVID-19 [Primary care, residential homes for the elderly, and COVID-19]. Semergen. 2020;46 Suppl 1:26-34. Spanish

7. Stall N, Sinha S. Why nursing homes are so vulnerable to COVID-19 catastrophe [homepage]. Toronto: Canada Project; 2020 Apr 2. Available from: https://www.theglobeandmail.com/opinion/article-why-nursing-homesare-so-vulnerable-to-covid-19-catastrophe/

8. EUROSTAT. Estrutura populacional e envelhecimento [homepage]. Luxembourg: EUROSTAT; 2019 [updated 2020 Feb 3]. Available from: https://ec.europa.eu/eurostat/statistics-explained/index.php?title=Population_structure_and_ageing/pt

9. PORDATA. BI de Portugal [homepage]. Lisboa: Fundação Francisco Manuel dos Santos; 2020. Available from: https://www.pordata.pt/Portugal/População+residente

10. Instituto Nacional de Estatística. Estatísticas da saúde 2018. Lisboa: INE; 2020.

11. Grupo de Estudos de Saúde do Idoso. Recomendações para IPSS, lares e ERPI durante a fase de mitigação e resolução da pandemia COVID-19 [Internet]. Lisboa: Associação Portuguesa de Medicina Geral e Familiar; 2020. Available from: https://apmgf.pt/wp-content/uploads/2020/06/vs87tnsm 1585777276259.pdf

12. World Economic Forum. The great reset [homepage]. World Economic Forum; 2020. Available from: https://www.weforum.org/great-reset/

\section{ENDEREÇO PARA CORRESPONDÊNCIA}

E-mail: rui.artur.nog@gmail.com 